\title{
CUIDADOS DO ENFERMEIRO VOLTADO À PREVENÇÃO DO DELIRIUM EM IDOSOS SOB CUIDADOS INTENSIVOS
}

Emerson Carneiro Souza Filho; UEPG; emersonsouza23122000@gmail.com

Gabriela Serighelli da Rosa; UEPG; serigheligabriela@gmail.com

Caroline Gonçalves Pustiglione Campos; UEPG; carolgonc@hotmail.com

Jacy Aurélia Vieira de Sousa; UEPG; jacy.sousa@gmail.com

\section{RESUMO}

Introdução: Delirium é uma síndrome representada por início agudo de disfunção cerebral, um nível alterado de consciência, desatenção e desorganização do pensamento. Uma condição relativamente comum nos cuidados críticos, principalmente em idosos e de prevenção pouco difundida, e que resulta em um maior taxa de mortalidade e tempo de internação. Objetivo: Analisar a produção científica sobre prevenção do delirium em pacientes em Unidades de Terapia Intensiva (UTI) por meio de intervenções não farmacológicas aplicadas por enfermeiros. Métodos: Trata-se de uma revisão integrativa de literatura. Foram selecionados nas bases de dados: SCIELO, PUBMED, CAPES e BDENF, no período de setembro de 2019 a fevereiro de 2020. Foram incluídos artigos relacionados à prática clínica do enfermeiro relacionada à prevenção do delirium em idosos internados em UTI, em inglês, português ou espanhol, disponíveis gratuitamente e na íntegra. Foram excluídos aqueles não relacionados ao cuidado de enfermagem, não realizados com seres humanos e que apresentavam em mais de uma base. Amostra final do estudo foi composta por 18 artigos nacionais e internacionais, publicados entre os anos 2010 e 2019. Resultados: Foram identificadas intervenções profiláticas aplicadas por enfermeiros para delirium, desde as mais básicas, como controle da luminosidade e dos ruídos, instalação de relógios, até intervenções mais complexas e tecnológicas como intervenções automatizadas de reorientação guiada pela voz de familiares e/ou pessoas do convívio do paciente, dentre outras que se mostraram eficientes. Conclusão: Foram identificadas interferências não farmacológicas aplicadas por enfermeiros que auxiliam na prevenção do delirium no paciente idoso.

Palavras-chave: Delirium; Saúde do Idoso; Enfermagem geriátrica; Prevenção.

Agradecimentos: A elaboração do trabalho não seria possível sem o apoio de alguns intervenientes. Assim sendo, pretendo agradecer a todos os que sempre me apoiaram e contribuíram para essa realização. À Professora Doutora Jacy Aurélia Viera de Sousa pela sua disponibilidade e compreensão, orientando e guiando o desenrolar do meu trabalho, manifestando sempre as suas opiniões enriquecedoras. A todos meus colegas de Iniciação Científica. À instituição de Ensino Superior UEPG (Universidade Estadual de Ponta Grossa) e ao CNPq (Conselho Nacional de Desenvolvimento Científico e Tecnológico) por todo apoio. 